\title{
Travessia da palavra: Haroldo Maranhão CElebra Machado de Assis
}

\author{
Crossing texts: Harold Maranhão celebrates \\ Machado de Assis
}

\author{
Sérgio Afonso Gonçalves Alves*
}

\begin{abstract}
RESUMO
Este trabalho analisa o romance Memorial do fim: a morte de Machado de Assis, de Haroldo Maranhão, sob a perspectiva do jogo enquanto processo de construção textual que se dá entre textos de autores e épocas diferentes. Será analisado o processo que permite a passagem (tradução), a travessia de um texto primeiro para um segundo, caracterizando-se como jogo literário e textual: o texto de Machado de Assis, tomado como ponto de partida de escrita de Haroldo Maranhão; mas tal não ocorre simplesmente como pastiche e sim como transcontextualização, a partir do estabelecimento de diferenças, releituras, críticas e, ao mesmo tempo, homenagem. O resultado indica um trabalho de leitura realizado pelo segundo autor sobre a obra do primeiro, e um criativo trabalho de reescrita a partir de especulações sobre a vida e as cartas de Machado de Assis.

Palavras-chave: travessia, jogo, transcontextualização.
\end{abstract}

* Professor Adjunto - Universidade Federal do Pará. 


\begin{abstract}
This work analyzes the novel Memorial do fim: a morte de Machado de Assis, by Haroldo Maranhão, under the perspective of gaming in the textual process of construction, which happens between texts of different authors and ages. In this work, we'll analyze the process that allows the translation, understood as a crossing between the first text into a second one, characterized as a textual and literary game: the text of Machado de Assis taken as starting point for Haroldo Maranhão's writing. Such thing does not occur as a simply pastiche, but rather as a transcontextualization, by the establishing of differences, rereading, criticisms and, at the same time, homage. The result is a process of work and reading, performed by the second author over the work of the first one; it is also a creative job of rewriting, derived from speculations about the life and the letters of Machado de Assis.
\end{abstract}

Keywords: crossing, game, transcontextualization.

Os livros de Haroldo Maranhão, de maneira geral, possuem uma natureza híbrida. Constituídos por várias vozes, tons, estilos e linguagens, surge neles, também, a possibilidade de contar e recontar a História, sob vários pontos de vista, escapando assim de ideias consagradas, aniquiladoras da língua plural, o que dá aos seus livros características de combate à uniformidade discursiva.

Dentre outras referências, os romances Memorial do fim e O tetraneto Del-Rei decorrem de um trabalho específico realizado pelo autor, que se debruçou sobre os textos de Machado de Assis e sobre a História do Brasil colonial para atualizar as vozes do autor de Dom Casmurro e de autores da literatura brasileira e portuguesa, respectivamente. Elementos de nossa historiografia (ficcional e não-ficcional) estão presentes nesses dois livros que nasceram de um árduo trabalho de leitura, ao qual juntou-se a imaginação do autor; o resultado é um complexo que se aproveita de fragmentos, de nomes e de aspectos da História e da literatura - é uma escritura que reescreve a tradição, sob ângulos diferentes, representando dados do passado e articulando-os em uma outra versão. Sob a pena do escritor paraense, o passado ganha asas, graças a um trabalho que, ao contrário do historiador, não condiciona os fatos a uma verificação prévia. 
Quanto à recepção crítica de Haroldo Maranhão, chamo a atenção para a crítica acadêmica de Rogério Lima e de Lucilinda Teixeira. o primeiro aborda o romance Memorial do fim a partir do processo de dissemiotização do signo, tendo em vista a sua articulação com a linguagem da modernidade e da pós-modernidade. $\mathrm{O}$ autor parte do entendimento de que o contexto inaugurado pela modernidade, que introduziu na literatura uma nova forma de estruturar a narrativa e o pensamento, esgotou-se, e uma nova voz dissonante se levanta, batizada de pós-modernismo, trazendo uma transformação para a cultura. Dá-se, então, um processo transformador, que recoloca o signo em uma nova roupagem, por meio do pastiche e não da simples reprodução, processo que o autor intitula dissemiotizador. Dissemiotizar o signo, segundo o ensaísta, significa colocá-lo em um novo parâmetro, em uma nova relação, a qual inaugura uma nova maneira de posicioná-lo diante da cultura.

Para Rogério Lima, o romance Memorial do fim instaura uma "total ambiguidade no universo ficcional machadiano, permitindo recuperá-los [os personagens e os contextos de Machado] para a criação de uma outra proposição de realidade ficcional" ${ }^{1}$ por meio da manipulação que o autor realiza com os personagens ficcionais e reais, criando uma ficção diferenciada. Desse modo, Haroldo Maranhão constitui-se como escritor pós-moderno, na medida em que seu romance escreve sobre "mundos concebíveis, ao menos imagináveis, porém irrealizáveis, inconcebíveis" ${ }^{2}$ - considerando que estas são características dos escritos pós-modernistas, segundo o mesmo autor.

Quanto ao segundo estudo Lucilinda Teixeira realiza, dentro do horizonte da crítica genética, um estudo dos originais de Memorial do fim. A estudiosa efetuou um levantamento comparativo entre o texto de Haroldo Maranhão e a obra de Machado de Assis, apontando com precisão as frases que Haroldo eliminou do original, com a intenção de mostrar o processo de criação do romance. A autora assinalou os deslocamentos das frases de um e de outro romancista, verificando a associação que se deu entre eles e a colagem do texto de Maranhão. Demonstrado esse mecanismo de associação, ficou claro que se trata de um processo singular, em que há articulação de fragmentos dos referidos autores, o que levou à montagem do romance até a sua conclusão. Nesse particular, a autora classifica os vários movimentos de montagem, concluindo, à luz da definição desse termo por Einsenstein, como "justaposição de dois planos de qualquer tipo que, ao serem unidos

1 LIMA, Rogério. O dado e o óbvio: o sentido do romance na pós-modernidade. Brasília: EDU/Universa, 1998.

2 Ibidem. p. 148-149. 
não efetuam simplesmente uma soma, mas criam um terceiro plano." ${ }^{3}$ Haroldo Maranhão une peças diversas de Machado de Assis, criando, por variada justaposição, uma nova peça com qualidades diferentes, além dos acréscimos criativos. Meu trabalho realiza, de certa forma, um diálogo com o ponto de vista dos estudiosos aqui citados, porém acrescenta o aspecto lúdico, visualizando o texto não só como montagem mas também como jogo.

Em relação à questão histórica, o ensaio de Marilene Weinhardt, intitulado Quando a história literária vira ficção, busca esclarecer os limites ou as aproximações entre as práticas discursivas histórica e ficcional. A ensaísta discute o peso e a relevância da ficção histórica contemporânea no quadro geral da literatura brasileira, indagando sobre suas características e variáveis, além de assinalar que ela tematiza a História, porém sem seguir os padrões convencionais do ensaísmo histórico e sem se ajustar ao modelo do romance histórico do século XIX, caracterizado por Lukács.

Para a estudiosa, sempre houve, na literatura brasileira, uma associação entre os discursos identitários e fundacionais, os quais já estiveram na ordem do dia em momentos em que era urgente a discussão da identidade nacional. A ficção histórica contemporânea continua a debater essas questões, abordando-as, entretanto, de dois modos diferentes: por meio da ficcionalização de personagens cuja existência empírica marcou a história literária e por meio da migração de personagens ficcionais dos textos canônicos para os novos textos.

No primeiro modo de abordagem da ficção histórica, a ensaísta inclui: Em liberdade, de Silviano Santiago, Cães da província, de Assis Brasil, Boca do Inferno, de Ana Maria Miranda e Memorial do fim, de Haroldo Maranhão. Entre os segundos, estão Enquanto isso em Dom Casmurro, de José Endoença Martins e Noturno, 1844, de Raimundo C. Caruso, dentre outros. A respeito do livro de Haroldo Maranhão, a autora destaca a composição de personagens reais e fictícios; a fusão do indivíduo Machado de Assis em vários narradores de sua obra; a mistura entre o escritor e os seus personagens; e, como não poderia deixar de salientar, a incorporação do discurso machadiano no texto de Haroldo Maranhão. Acredito que Memorial do fim se inclui nos dois modos de abordagem, uma vez que processa não apenas a ficcionalização de Machado de Assis, como também a de personagens que compõem a obra do escritor fluminense e de alguns de seus amigos.

Para a abordagem do romance Memorial do fim: a morte de Machado de Assis como jogo/travessia/tradução entre textos, foi necessária 
uma leitura atenta das advertências de romances de Machado de Assis e de cartas do autor de Dom Casmurro a alguns amigos, articulando estas àquelas no processo de construção do romance Memorial do fim. Nesse jogo de interesses que se deu entre Haroldo e Machado, o primeiro parte da ideia de prestar uma homenagem ao seu autor preferido, reescrevendo, à moda do segundo, textos não publicados, que ficaram guardados para virem à tona em outra ocasião. Haroldo Maranhão age, então, como suposto editor/ escritor de textos desconhecidos de Machado.

Sabe-se que a advertência ao romance Esaú e Jacó registra que os volumes encontrados na secretária do conselheiro Aires com a indicação em algarismos romanos de I ao VI fazem parte do Memorial. O sétimo livro, intitulado Último, é uma narrativa e não faz parte do diário de lembranças do conselheiro. Os outros seis volumes, escritos durante os lazeres do ofício, compunham o Memorial e serviriam, na melhor das intenções, para matar o tempo da barca de Petrópolis, caso fossem aparados das páginas mortas ou escuras. As páginas desbastadas do diário, que não serviram para publicação - pode-se imaginar -, foram parar na gaveta, permanecendo inéditas, ficando no ar a sugestão, registrada na advertência ao romance Memorial de Aires, de que poderiam vir a ser publicadas um dia, através de algum editor ou admirador do conselheiro. Desta forma, o editor dos dois romances deixa para um terceiro "as sobras e os restos" que ficaram conservadas na secretária, após a morte do autor, conforme se lê na advertência ao Memorial de Aires:

Não houve pachorra de a redigir à maneira daquela outra, - nem pachorra, nem habilidade. Vai como estava, mas desbastada e estreita, conservando só o que liga o mesmo assunto. $O$ resto aparecerá um dia, se aparecer algum dia ${ }^{4}$.

A partir desse ponto, pode-se atar um laço entre a ficção e a vida, relacionando a advertência àquilo que Machado de Assis registra em cartas aos amigos. Machado, já atingido pela doença que o levaria à morte, declara ser o Memorial de Aires seu livro derradeiro, pois já não encontra forças para as "folias literárias", conforme escreve aos amigos José Veríssimo e Joaquim Nabuco. $\mathrm{Na}$ advertência ao último romance, a falta de estímulo para escrever se traduz por falta de paciência e habilidade; nas cartas aos amigos são comuns os registros de cansaço e falta de disposição causados pela doença, pelo desgaste da visão e pela ausência da companheira - que, sabe-se através de biografias, realizara a revisão do penúltimo romance. Há, portanto, uma aproximação entre a constatação das correspondências e as 
palavras da advertência ao Memorial de Aires no que se relaciona à falta de habilidade para redigir à maneira da outra.

Hipoteticamente, Machado poderia escrever outro romance, caso encontrasse forças suficientes, a partir dos restos desbastados daquilo que fora publicado no Memorial de Aires. Essa hipótese nada absurda de aproveitar os cortes realizados no último romance é levantada em uma das últimas cartas enviadas a Nabuco, com data de 08 de maio de 1908, na qual o escritor confessa que doará à Academia os originais e alguns inéditos. Estes papéis, pode-se ainda especular, estariam relacionados aos restos de escrita que permaneciam inéditos até a data da correspondência.

É a partir dessas especulações que Haroldo Maranhão escreveu o seu romance Memorial do fim, a morte de Machado de Assis. Este romance, de tom confessional e ritmo morrinhento, narra os últimos momentos do autor de $D$. Casmurro, numa linguagem envolvida em mistérios e ambientes fechados, onde há pouca penetração de luz, que sugerem as páginas escuras rejeitadas pelo editor de Esaú e Jacó e Memorial de Aires.

Haroldo Maranhão reúne fragmentos da escrita machadiana e supostos elementos da vida do escritor, fazendo de seu romance uma experiência textual lúdica com os últimos dias de Machado, sugerindo que o Memorial do fim fora escrito pelo próprio conselheiro Aires, numa escrita feérica, imaginada a partir de seu leito de morte. Essa hipotética conclusão é favorecida por vários indícios, como os que ocorrem na apresentação da primeira edição do romance de Haroldo, datado de 1991.

Esta primeira edição apresenta capa de cor marrom escuro, com as páginas internas amareladas, o que sugere a ação do tempo sobre as páginas brancas de velhos cadernos, cobertas de poeira, o que lhe dá uma espessura áspera. São indícios de um objeto guardado por décadas, um achado que Haroldo Maranhão - um suposto editor - se encarregou de publicar. Essa hipótese insinua-se também no posfácio, pois o editor assume a responsabilidade de organizador de textos fragmentados, dando conta de que o romance fora armado como um puzzle de palavras. Além disso, o editor confessa fazer pastiche de Machado como forma de homenagear o autor.

o suposto editor do Memorial do fim organiza a escrita de Machado de Assis quase aleatoriamente, sem a preocupação de construir um enredo linear, tradicional, com início, meio e fim. Com isso, a estória da morte é contada através de fragmentos colocados um após o outro, sem a preocupação de manter uma coerência. Como resultado dessa ordem, surge uma escrita labiríntica, tortuosa, com várias entradas, portas e janelas, que levam o leitor a várias direções, pois cada elemento do enredo oferece muitas opções e interpretações diferentes. 
Aproveitando-se de hipóteses reais e fictícias, o texto se autorrecria, retomando imagens com as quais engendra uma série de outras imagens, construindo-se em mise-en-abyme, levantando outras hipóteses relacionadas à ficção do escritor fluminense, à sua escrita, aos seus personagens e aos seus amigos. Com isso, não se percebe a presença de uma voz narrativa ou de um narrador, e sim de vozes narrando alternativamente, o que traz ao texto uma maior liberdade de expressão, já que não há a predominância de uma ideologia ou de um caráter. O resultado consiste num jogo no qual se encenam prováveis acontecimentos da vida de Machado de Assis, como a paixão secreta do escritor e seu desejo de casar in extremis, as visitas ao escritor doente, como a do jovem admirador e da futura escritora, e outros mistérios construídos como um jogo armado.

Para encenar a travessia de personagens que vão transitar de um texto a outro, Haroldo Maranhão utiliza a metáfora da porta. Atravessar portas é condição de participação no jogo do Memorial, como o que ocorre com José Veríssimo e Marcela Valongo. José Veríssimo de Matos, ao chegar ao chalet, encontrara a porta entreaberta ou entrefechada, o que tornará possível a presença de personagens do escritor fluminense no texto de Haroldo Maranhão:

Nos últimos dias, alguém decretara o procedimento, para não trancá-la e obstar visitas indecisas, tampouco deixando-a franqueada, a aliciar os vadios que não distinguem entre o seu e o dos outros. Teriam passagem natural os velantes costumeiros, escassos e pontuais ${ }^{5}$.

A acessibilidade ao interior da casa, facultada por esse alguém, está vinculada à passagem de elementos de um texto a outro (tradire: travessia), transposição metaforizada (tradire: traição), no procedimento que alterou a rotina na casa do morador sozinho, onde "descer e subir escadas não é assunto manso; é deliberação visceral que tange raias inauditas" devendo essa matéria ser tratada em um tomo ou dois. A decisão de descer ou subir escadas, portanto, exige demoradas reflexões que não cabem em linhas distraídas, pois é tema que transcende os máximos limites, ou seja, o propósito depende do personagem de ultrapassar a linha que separa a ficção de Machado e a ficção de Haroldo Maranhão. Um exemplo disso consiste na hesitação de Marcela Valongo em ultrapassar a porta do Cosme Velho (que significa "saltar" (travessia) para o texto de Haroldo Maranhão) ou dar uma volta na matriz (ou seja, permanecer no texto de Machado de Assis). 
O capítulo "O bom uso e o mau uso das portas" começa com uma afirmação que pode ser do editor do Memorial do fim: "Ninguém transpõe portas pela razão de que ocasionalmente se mantenham abertas" 7 . Levando-se em consideração que o verbo "transpor" possui sentidos diferentes, como inventar, criar, reinventar; ultrapassar barreiras, quebrar tabus, transgredir; a palavra do editor, como organizador de fragmentos, assume todos esses sentidos, numa atitude pautada pela liberdade de manipular os personagens do mundo machadiano e editá-los de acordo com seu interesse. É como se o autor, que assume o caráter transgressor, estivesse ultrapassando ou transcendendo limites impostos, conforme justifica nas seguintes palavras:

O arbítrio seria do dono da porta, ou do violador dela; este, indivíduo de maltas, a adjudicar-se o poder de abri-la com rudeza maior ou menor, dependendo da qualidade da madeira e do humor ${ }^{8}$.

Com o súbito aparecimento de Marcela Valongo, a passagem de um lugar a outro ocorre de maneira a colocar em jogo personagens de natureza oposta. Marcela Valongo, personagem gerada no mundo machadiano, atravessa livremente para um outro texto, para a outra narrativa, porém levada por um motivo muito especial, de acordo com as seguintes palavras do editor: "D. Marcela Valongo não ultrapassou por ultrapassar a porta do Cosme Velho, apenas porque surpreendesse franqueada a meia folha" ${ }^{\text {. o que }}$ teria impulsionado Marcela Valongo a essa travessia foi uma necessidade interior de empurrar, ousar, ir adiante, sair da casa onde se encontrava, andar com os próprios pés, sem chapéu, e desembaraçar-se do véu para dirigir-se à casa do enfermo, pois ela precisava e queria rever Ayres.

A presença de Marcela no Cosme Velho provoca alvoroço entre os amigos de Machado, que levantam a hipótese de sua presença na casa do enfermo. Mário de Alencar, que chegava para saber do doente, buscou averiguar a estranha novidade transmitida por Veríssimo em carta, a propósito da presença de parfum de femme na casa, pois era pessoa de prestar atenção a tudo, assim não deixaria de perceber pessoas de imoderado procedimento. No entanto, Mário de Alencar não percebe anormalidade, aumentando a ambiguidade do romance: o jogo de palavras ganha força a cada frase, desdobrando-se em jogo de esconde-esconde, de busca do elemento oculto, escondido entre tantos outros. No jogo encenado do romance, o vencedor 
é o objeto de procura, no caso aqui demonstrado; o elemento procurado é Marcela, que passa a dominar a cena, ludibriando o detetive, com a ajuda de outros elementos que se tornam seus cúmplices.

Marcela Valongo possuía a chave da casa, que certamente usava nas ocasiões necessárias. No entanto, naquele momento, penetrara nos aposentos do enfermo por encontrar a porta entreaberta, caso contrário "ela mesma a teria franqueado com a chave gêmea que mantinha no interior de um medalhão de ouro" ${ }^{10}$. Tudo leva a crer que obteve tal chave das mãos do próprio morador. Tal mobilidade transforma os personagens, que assumem uma natureza transitiva, movimentando-se entre um lugar e outro, ou entre dois lugares ao mesmo tempo, conforme demonstra a hesitação de Marcela entre visitar o doente e dar uma volta na matriz. Essa dinâmica permite que o conselheiro Ayres seja, concomitantemente, um personagem de Machado de Assis e uma réplica de Machado de Assis, ao qual se acrescentam ainda marcas de outros personagens de romances.

Por que a presença de Marcela Valongo provocara tanto alvoroço entre os amigos do enfermo, principalmente em José Veríssimo, que se declara um roceiro obidense que sempre duvidou dos bichos-do-fundo, para afastar qualquer insinuação de ter visto visagens? Por que José Veríssimo escreve a Medeiros dando conta da presença de figura feminina que lhe causou sinceros solavancos? O trecho seguinte é um fragmento da carta de José Veríssimo, dando conta de seu espanto:

Não escutei passos fortes, não. Um vago farfalhar de panos fartos? Não também. Insinuante aroma nascido em epiderme maciíssima? (estava e estou de narinas obstruídas, a crédito de uns saldos de influenza). Entrevi um vulto mal visto e logo sumido? Sou, sabes, catacego, com o bardo Camões. Então? A voz que me causou sinceros solavancos veio em conduto por onde passam as harmonias raras. ${ }^{11}$

Para encontrar uma explicação, o leitor deve voltar ao primeiro capítulo, em páginas que antecedem a carta de Veríssimo a Mário de Alencar. Diante da presença súbita de Marcela, José Veríssimo, sobressaltado ao ouvir a voz otimamente modulada que lhe cumprimentara, tenta, a todo custo, recuperar o equilíbrio que de todo se rompera no ambiente. Estava diante de uma figura que, provavelmente, conhecera, sim - mas na ficção do mestre. 
Diante de tal descoberta, José Veríssimo perturba-se, encenando a mesma situação do contato entre Nogueira e D. Conceição, do conto Missa do galo, na noite de natal. Os papéis que desempenham se colam aos dos personagens do conto, vivendo ambos a mesma situação: "falavam baixo, ela mais que ele, ela mais senhora da situação e da casa, ele num pinote decaído de amigo íntimo a visitante cerimonioso" ${ }^{12}$. $O$ adolescente do conto, imantado pelos movimentos seguros e insinuantes de D. Conceição, perde o equilíbrio, estampado no tom de voz, que cabe a ela controlar. No conto, devem falar baixo para não acordar a mãe de Conceição, no romance Memorial do fim devem tomar cuidado para não despertar o próprio conselheiro.

No entanto, há no texto a hipótese do conhecimento prévio do crítico em relação a Marcela Valongo, conforme demonstra o editor: "José Veríssimo de Matos leu-lhe o pensamento como a uma página impressa"13. o texto insinua que José Veríssimo conhecia o personagem de papel das leituras de contos e romances de Machado de Assis, sugerindo ao leitor que Marcela Valongo fora retirada dos escritos do enfermo, representado pelo conselheiro Ayres, pois as descrições físicas de Marcela Valongo coincidem com as características físicas de muitos personagens femininos de Machado de Assis - como por exemplo, os modos severos e esbeltos, lábios de mais caldo que uma laranja, o garbo outoniço dos quarenta, a doçura dos olhos claros $^{14}$ etc.

Estes são alguns dos elementos que Haroldo Maranhão transcontextualiza para o ambiente do Memorial do fim. Sob este aspecto, o romance também se constitui enquanto paródia da obra machadiana. Definido por Hutcheon como repetição com diferença, ou repetição com distância crítica, ${ }^{15}$ a paródia é um elemento do discurso que, ao retomar outros textos, estabelece uma relação de "transcontextualização" ${ }^{16}$. Linda Hutcheon esclarece o termo a partir do romance $O$ nome da rosa, de Umberto Eco, dizendo que este "transcontextualiza" personagens, pormenores do enredo e até citações verbais de $O$ cão dos Baskervilles, de Conan Doyle. Nessa dinâmica, Sherlock Holmes é William de Baskerville, Watson é Adso; os personagens de Doyle são transplantados para o ambiente medieval de monges e o trabalho detetivesco é análogo à interpretação textual. Por outro lado, o ataque do monge Jorge de Borgos à propriedade do riso fornece igualmente a entrada para outro complexo parodístico, que remete à obra de Jorge Luis Borges.

Idem, ibidem, p.13.

Idem, ibidem, p.13.

Idem, ibidem, p.13.

HUTCHEON, Linda. Poética do pós-modernismo. Imago: Rio de Janeiro: 1991, p.47. HUTCHEON, Linda. Uma teoria da paródia. Edições 70: Lisboa: 1985, p.23. 
Sob esta noção, o discurso do Memorial do fim se constrói então através de enunciados complexos, que redimensionam o texto traduzido e o texto tradutor, carregando-os de significados e palavras polissêmicas. A tradução se constrói como narrativa sobre as outras estruturas, cujas molduras são rompidas pela presença de múltiplas vozes da obra tradutora. Nela, a voz descentraliza-se e multiplica-se, sugerindo que o texto se constrói como uma rede de significação, articulado com outros textos pré-existentes e com sistemas de significação literários e não-literários, num processo que estabelece uma relação de aproximação e, ao mesmo tempo, de afastamento.

O texto de Haroldo Maranhão traz de volta as vozes ficcionais de Machado de Assis, num processo remissivo que faz um caminho de volta e que, ao mesmo tempo, remete a outros contextos, produzindo o diálogo intertextual. Como o texto de Maranhão mantém-se fiel ao estilo de Machado, dele conservando as virtudes e o ritmo de escrita, poder-se-ia pensar em pastiche, quando o texto segundo se projeta como sombra do primeiro: um "texto como outro" ${ }^{17}$. Sob essa perspectiva, a cópia de Machado se deu de forma inevitável, como o modo possível de ter acesso às estruturas de linguagem do passado e de trazer a presença de Machado para o texto do presente. Mas essa presença se faz transcontextualizada, reconstruída com o outro, que é a escrita de Maranhão.

Ao interferir na escrita de Machado de Assis, Haroldo Maranhão assume a tarefa de "escarafunchar arquivos e textos, levantar dados, fazer conjecturas, seguir pistas labirínticas, decifrar letras esmaecidas, correr atrás de cartas e diários perdidos, maquinar, tramar, fraudar..."18. Na trama do texto, recria situações, modificando o rumo dos fatos conhecidos, graças à postura assumida de articulador de textos, ou falso editor.

Verifica-se, então, na conversão do texto de Machado para o de Haroldo, que o contexto é invertido. Em Haroldo, há os mesmos personagens e as mesmas posturas, porém as relações são ironicamente diferentes no contato com os personagens "reais", amigos de Machado. Percebe-se que, ao contrário da paródia tradicional, a crítica irônica não se estabelece na forma de riso ridicularizador, mas se realiza naquilo que o próprio autor chama de homenagem. Na verdade, Memorial do fim reconstitui em forma de homenagem a obra de Machado de Assis; há inúmeras passagens em que tal homenagem se dá em forma de jogo textual, demonstrados, por vezes, em troca de nomes e papéis, permitindo várias possibilidades de movimentação,

17 SCHNEIDER, Michel. Ladrões de palavras. Editora da UNICAMP: São Paulo, 1990. p.81.

18 MIRANDA, Wander Melo. A liberdade do pastiche. 34 Letras. Rio de Janeiro, v.3, p.172-177, 1989. 
permeando muitos caminhos que desencadeiam as jogadas, como se houvesse estradas possíveis, nas quais cada elemento se movimenta e desempenha um papel. Entre tantas passagens que poderiam ilustrar a homenagem de Haroldo a Machado, elegemos a seguinte:

Hilda é Hylda, e Hilda é Leonora. Leonora?

- Hilda, façamos um jogo.

- Um jogo, Sr. Machado?

- Nada de gamão ou de xadrez ...

- ... É um jogo. Nosso. Só nosso. Você passa a ser Leonora ...

- Nosso jogo. Eu serei ..., bem. Pensei em Florestan. Não, não. Florestan é espanhol. Eu serei Aguiar ou o Ayres. Ayres também é espanhol, mas também eu gosto de Ayres.

- ... minha memória é pouca para as matérias aborrecidas. Tudo o que é agradável eu guardo na minha gaveta mágica.

- Gaveta mágica?

- Tenho. Uma gaveta mágica. É o meu segredo.

- Segredo?

- Claro. Se é mágica tenho que guardar segredo. Não digo a ninguém ...

- ... Agora, tem uma: Leonora, não é Leonoura, como cenoura; uma letra desequilibra, desequilibra ou não desequilibra? Leonora eu tirei da caixa mágica. ${ }^{19}$

Este diálogo apresenta um quadro que norteia quase todo o conjunto da obra de Haroldo Maranhão, observado ainda em outros romances do autor: o jogo com os nomes, o entrelaçamento de textos associado à montagem, que constroem o texto como tecido, emaranhado de fios que conduzem a um diálogo de autores e textos.

Ainda assim, tal homenagem, sob nosso ponto de vista, não ocorre de forma passiva, mas desestabilizadora de uma hierarquia, pois não se trata de uma simples imitação ou apropriação, empobrecedora do texto segundo, mas sim de uma confrontação, uma recodificação moderna que estabelece a diferença no coração do semelhante. A homenagem aqui não evita, entretanto, alterações de sentido no texto homenageado. Segundo Thomas M. Greene $^{20}$ : "Toda imitação criativa mistura a rejeição filial com o respeito, tal como toda a paródia presta a sua própria homenagem oblíqua".

Portanto, o texto de Haroldo Maranhão é um tecido narrativo que entrelaça elementos diversos da obra e de acontecimentos da vida de Machado de Assis. Cada parágrafo, frase ou fragmento de frase abre portas ou janelas que remetem o leitor para um mundo recriado de palavras, funcio- 
nando como hipertextos. O trecho seguinte metaforiza a abertura de portas e janelas para outras dimensões:

Cuidemos portanto que D. Marcela Valongo não ultrapassou por ultrapassar a porta do Cosme Velho, apenas porque surpreendesse franqueada a meia folha. Impante caminhou, impante, sim, com a familiaridade chancelada (parece claro) pelo Conselheiro, que empregou o próprio sinete na papa de lacre. ${ }^{21}$ (MARANHÃO, 1991, p. 15)

Neste sentido, cada elemento do Memorial do fim constitui um apêndice que se abre para várias possibilidades de leituras, em várias direções, espraiando signos e constituindo-se como texto estrelado, levando o leitor a percorrer caminhos labirínticos. O tipo de travessia realizada entre os textos consiste em um processo de integração, revisão, inversão e transcontextualização, restaurando a ideia de um diálogo tenso, paródico com o passado que deseja recompor pelo interesse histórico e por meio da palavra de outrem, sem deixar de se estabelecer como forma particular de jogo textual e ficcional.

\section{REFERÊNCIAS}

ASSIS, Machado de. Memorial de Aires. Obras completas v.1. São Paulo: Nova Aguilar, 1992. GREENE, Thomas M. The light in Troy: imitation and discovery in Renassaince Poetry. New Haven, Yale University Press. 1982.

HUTCHEON, Linda. Poética do pós-modernismo. Rio de Janeiro: Imago, 1991.

HUTCHEON, Linda. Uma teoria da paródia. Lisboa: Edições 70, 1985

LIMA, Rogério. O dado e o óbvio: o sentido do romance na pós-modernidade. Brasília: EDU/ Universa, 1998.

MARANHÃO, Haroldo. Memorial do fim: a morte de Machado de Assis. São Paulo: Marco Zero. 1991.

MIRANDA, Wander Melo. A liberdade do pastiche. 34 Letras. Rio de Janeiro, v.3, p.172-177, 1989.

SCHNEIDER, Michel. Ladrões de palavras. São Paulo: Editora da UNICAMP, 1990.

TEIXEIRA, Lucilinda. Ecos da memória: Machado de Assis em Haroldo Maranhão. São Paulo: Annablume, 1998.

Submetido em: 29/08/2013

Aceito em: 09/05/2014

21 MARANHÃO, Haroldo. Memorial do fim. Op. cit., p.15. 